\title{
Zwierzę, które pisze - mit o nimfie lo w Metamorfozach Owidiusza
}

\section{The animal, which writes - the myth of the nymph lo in Ovid's Metamorphoses}

\author{
|Krzysztof Witczak
Uniwersytet im. Adama Mickiewicza w Poznaniu
}

\begin{abstract}
The ratio of human to an animal is one of the most important relationships between nature and culture. The study of this issue can bring a new look on the body, especially the fact that today in the era of already developed animal studies. Ovid's Metamorphoses were treated as text-pattern, which makes the transformation - the process of incorporation into an animal. The article is about the interpretation of the myth of the transfiguration mistress of Zeus nymph Io into a heifer and her attempts to communicate with the world of people using the letters. The myth of Io can thus be regarded as a story initialized to the creation of writing (the save characters), and the same placing as the animal in the center of the story - as the beginning of a discussion on the relationship occurring between what exists (nature) and what is produced (culture).
\end{abstract}

Key words: animal studies, Ovid, culture, body

Streszczenie: Stosunek człowieka do zwierzęcia obrazuje istotny związek między naturą i kulturą, a badanie tego zagadnienia może przynieść nowe spojrzenie na ciało, zwłaszcza na to, które dziś w dobie rozwiniętych już studiów dotyczących kwestii nieantropocentrycznych gubi ludzką postać. Metamorfozy Owidiusza potraktowane zostały jako tekst-wzorzec, w którym dokonuje się transformacja - proces wcielenia się w zwierzę. Artykuł dotyczy interpretacji fragmentu dzieła poety opowiadającego o historii przemienienia kochanki Zeusa nimfy Io w jałówkę oraz jej prób porozumienia się ze światem ludzi za pomocą pisma. Mit o Io może być zatem traktowany jako opowieść inicjalna powstania pisma (systemu zapisywania znaków), a samo umieszczenie postaci zwierzęcej w centrum opowieści jako początek dyskusji o relacji występującej między tym, co zastane (naturą), a tym, co wytworzone (kulturą).

Słowa kluczowe: zwierzę, Owidiusz, kultura, ciało

Nie możemy siebie poznać w pełni, jeśli nie poznamy również natury wszystkich zwierząt. (św. Ambroży, Heksametron) 
Jednym z podstawowych rozpoznań, obecnych w świadomości powszechnej, jest przeświadczenie o istnieniu różnic między tym, co ludzkie, a tym, co zwierzęce czy poza-ludzkie. Ich określanie miało istotny wpływ na kulturowe konstruowanie tożsamości człowieka. Jednocześnie już od starożytności poszukiwano miejsc łączących różne formy bytów, również te, które przynależały jedynie do sfery wyobrażeń - jak monstra i hybrydy. Owidiusz w swoim poemacie Metamorfozy przedstawia ten problem, odwołując się do zasady zmienności rządzącej światem. W kulminacyjnym momencie jednej z takich przemian (w micie o Io) dokonuje się przejście od zwierzęcia poddanego bezlitosnej woli bogów do zwierzęcia przełamującego własne niemożności i komunikującego się z otoczeniem:

Chciałaby do Argusa wyciągnąć ramiona, prosząc o litość, ale nie ma ramion, aby Argusa objęły. Usiłując się skarżyć, tylko ryczy, a ryk własny ją przeraża. Przychodzi na te łąki, gdzie tak często się bawiła na brzegu Inacha, widzi odbite w wodzie swoje rogi, zdumiona sama od siebie ucieka. Nie wiedzą ani Najady, ani ojciec nie wie, kim jest; idzie za ojcem, za siostrami, daje się głaskać i podziwiać. Ojciec rwie trawę, jałówce podaje, ona dłoń liże, ręce ojcowskie całuje. Płacze; gdyby mówić umiała, błagałaby ratunku, wymówiłaby swe imię, powiedziała, co się stało. Zamiast słów kopytem znaczy litery na piasku, smutną przemianę swej postaci opowiada (Owidiusz 1995, 28-29).

W przywołanym powyżej obszernym fragmencie zarysowują się podstawowe problemy, które pragniemy omówić w niniejszym szkicu. Już w tym miejscu rozważań należy zwrócić uwagę na trzy kwestie: zastanawiająca jest po pierwsze zmiana, która dokonuje się w ciele bohaterki, po drugie opis podmiotu zwierzęcego i próba przełamania wynikającej z metamorfozy bariery komunikacyjnej, po trzecie wreszcie - zagadnienie początku pisma.

Zwierzęcość w myśli greckiej mieściła się między dwoma wielkimi kategoriami: ciągłości bytów i różnic między nimi. Stagiryta w swojej Zoologii następująco opisuje problemy związane z wyodrębnianiem poszczególnych gatunków: „Natura zatem stopniowo przechodzi od jestestw nieżywotnych do zwierząt i dzięki tej ciągłości nie pozwala dostrzec granicy, która oddziela jedne od drugich, ani określić, do której z dwóch grup należy forma pośrednia" (Arystoteles 1982, 305). Wszystkie organizmy należą zatem do - przywołując słynne określenie Arthura Lovejoya - „wielkiego łańcucha bytów", hierarchicznego porządku, w którym każdy otrzymał swoje miejsce. Powróćmy jednak do wyodrębnionej na początku dychotomii - ciągłości i różnicy. Można ją również ogólnie przedstawić jako rozbieżność między dwiema postawami filozoficznymi obecnymi w myśleniu starożytnych - stałością i zmiennością. Pierwsza postawa, omówiona wcześniej w odniesieniu do dzieł Arystotelesa, była również obecna w pracach Platona. Druga, postulująca zmianę, reprezentowana była przez Heraklita oraz Pitagorasa. Warto podkreślić, że ostatni z wymienionych sytuował się bardzo blisko poglądów samego Owidiusza, który w Metamorfozach zawarł parafrazę jego koncepcji: 
Nie ma niczego na całym świcie, co zachowywałoby swój kształt. Wszystko płynie i każda rzecz powstaje jako zjawisko zmienne. Nawet sam czas przepływa, będąc w ciągłym ruchu, podobnie jak rzeka: ani rzeka, ani chyża godzina nie może bowiem zatrzymać swego biegu. Ale jak nadciągająca fala naciska i popycha następną, a na nią samą naciera poprzednia, tak samo czas ucieka, jednocześnie następują i wciąż jest nowy. To, co kiedyś było, przestaje istnieć, a powstaje to, czego nie było, i cały proces raz jeszcze zaczyna się od początku (Owidiusz 1995, 416).

Metamorfoza stanowijednązgłównychzasad kompozycjiOwidiuszowego świata, „stałość przemian” dopełnia opisywanie czasu w porządku cyklicznym, charakterystycznym dla mitów. Można tu mówić o zasadzie zmienności, która nie objawia się jedynie w przywoływaniu elementów fantastycznych, ale ma swoje uzasadnienie w sposobie myślenia starożytnych. Ich wizja świata opierała się bowiem na binarnym rozróżnieniu stałości i zmiany, przekształcających rzeczywistość. Platon w Protagorasie ukazuje paradoksalność tej relacji właśnie w odniesieniu do człowieka i zwierząt (Platon 1958, 323). Filozof twierdzi, że wszystkie byty zostały stworzone w jednym akcie bez przynależnych im zdolności. Miały one zostać nadane poszczególnym stworzeniom przez Epimeteusza i Prometeusza. W wyniku nieroztropności tego pierwszego ród ludzki nie otrzymał żadnej umiejętności, co naprawił dopiero drugi brat, wykradając ogień bogom. Człowiek nie jest w tej historii istotą wyróżnioną na tle natury, ale bytem równorzędnym wobec innych stworzeń. Doskonale uzupełnia to przywołaną wcześniej koncepcję ciągłości bytów. Światy ludzi i zwierząt są zarazem dalekie i bliskie, są podobne i odmienne, wyrastają jednak z jednego źródła - siły natury.

\section{Zooestetyka/Zoofilologia}

Niedostrzegalną ciągłość oraz związaną z nią współobecność ludzi i zwierząt w świecie w interesujący sposób próbują oddać teksty literackie. Należy zastrzec, że literatura, w której pojawiają się zwierzęta, narażona jest jednak na wiele niebezpieczeństw, z których największe to niewątpliwie: traktowanie tych istot jako przedmiotów kulturowo umacnianej władzy człowieka, przyjmowanie antropocentrycznej perspektywy do opisania ich doświadczeń, pomijanie podmiotowości zwierząt, a przede wszystkim powierzchowna analiza. Tematyka zwierzęca powinna być opisywana zawsze z uwzględnieniem aspektu komunikacyjnego. Oprócz dostrzeżenia obecności takiego bohatera należy również zwrócić uwagę na sposób, w jaki zostaje on obdarzony głosem. W tym kontekście Derrida wskazuje na połączenie szeroko rozumianej poezji i zwierzęcości: materii języka, z której wyrasta praktyka artystyczna, i pewnej wspólnej wszystkim istotom przestrzeni dźwiękowej (Derrida 2011, 124). Jak stwierdza Aleksander Nawarecki, taki sposób badania tekstu należałoby określić mianem „zoofilologii”. Powinna ona „usłyszeć” głos zwierząt (w szczególności ten, który wkrada się do utworu przez środki językowe, zwłaszcza onomatopeje) oraz uwzględnić jego dwa wymiary: afirmację i afektywność. Początkowe 
uznanie atawistycznego powiązania komunikacji przechodzi w odwołanie się do zmysłów, które umożliwiają naturalne porozumienie ,,wspólnej odmienności" światów zwierząt i ludzi. Labilny charakter takiego podejścia, oparty na badaniu odczuć i śladów, w opinii badacza pozwoliłby zoofilologii pozostać ,,wierną duchowi literatury i szalonej utopii poszukiwania języka ze zwierzętami" (Nawarecki 2011, 15). Taka postawa zapewnia, według badacza, pogodzenie filologicznego zainteresowania narracją przy jednoczesnym zachowaniu ,,atawistycznego śladu” - związku wszystkich istot.

Zwierzę w tekście literackim, zdaniem Nawareckiego, winno być dostrzeżone i zbadane jako podmiot uczestniczący. Odkrywanie nieantropocentrycznego ujęcia nie zawsze wiąże się jednak z ,,bezgraniczną otwartością i prostą afirmacją pozaludzkiego" (Grochowski 2013, 10). W proponowanych ujęciach tematyki zwierzęcej dochodzi często do usytuowania tych bohaterów wobec nadrzędnej pozycji człowieka. Wojciech Przybyła przedstawia różne aspekty takiej obecności: zwierzę w funkcji kultowej i ponadnaturalnej (przybliżenie kontaktu z naturą i twórcą bytów w odwołaniu do ciągłości bytów), zachowanie zwierząt tłumaczące powstania jakiegoś zjawiska, zwierzę objawiające się w symbolice siły Dobra i Zła oraz zwierzę jako obiekt fantastyczny (Przybyła 2011).

Annę Martuszewską, na którą powołuje się Przybyła, interesował przede wszystkim aspekt metempsychozy: zjawiska wcielenia się duszy ludzkiej w roślinę lub zwierzę (Martuszewska 1993, 6). Takie zespolenie bytów bywa częstym doświadczeniem bohaterów opowieści starożytnych. Szczególnie jest to widoczne u Owidiusza. W przywoływanym wcześniej fragmencie analizowanego mitu czytamy, że Io: „Chciałaby do Argusa wyciągnąć ramiona, prosząc o litość, ale nie ma ramion, aby Argusa objęły. Usiłując się skarżyć, tylko ryczy, a ryk własny ją przeraża" (Owidiusz 1995, 28). Bohaterka doświadcza wcielenia, zachowując wspomnienie o byciu człowiekiem. Dlatego uderza ją niezborność adaptacji w sferze cielesnej, nieprzystosowanie somatyczności do prawdziwej natury. Jednocześnie obecne w micie przekonanie o ,zasadniczej i niedającej się wymazać solidarności życia (...) przerzuca pomost nad bogactwem i różnorodnością form" (Cassirer 1977, 176). Bohaterowie narracji o metamorfozie mogą przejść $\mathrm{w}$ inną postać bytu, ponieważ $\mathrm{w}$,,odczuciu mitycznym i religijnym przyroda staje się jedną wielką społecznością, społecznością życia”. Cassirer zauważa ponadto, iż taki porządek nie jest antropocentryczny:

W tej społeczności człowiek nie otrzymuje specjalnej pozycji, jest jej częścią, ale pod żadnym względem; nie stoi wyżej niż wszyscy inni jej członkowie, Życie ma tę samą godność religijną w najniższych i w najwyższych formach. Ludzie i zwierzęta, zwierzęta i rośliny wszystko to znajduje się na tym samym poziomie (...) Spotykamy się także z tą samą zasadą - z zasadą solidarności i nieprzerwanej jedności życia, kiedy od stosunków przestrzennych przechodzimy do stosunków czasowych (Cassirer 1977, 177).

Mit, w opinii Cassirera, opisuje jedność istnień, u Owidiusza ta relacja nie jest już tak wyraźna. Metamorfozy traktowane są często jako zastępcze 
formy istnienia, co wyraźnie wskazuje, że odejście od porządku mitycznego powoduje zaburzenie równości. Jak przekonuje Anna Barcz: „Ludzki, nowożytny i wyemancypowany podmiot poznania przestaje być interesującym punktem odniesienia" (Barcz 2013, 61).

\section{Zwierzenia}

Powróćmy zatem do cytowanego na początku mitu. Owidiusz przywołuje w nim historię nimfy Io, która została zamieniona przez Zeusa w jałówkę po to, by ukryć ich romans przed Herą. Zazdrosna małżonka nie daje się obłaskawić historią o niewiadomym pochodzeniu zwierzęcia i prosi męża o podarowanie jej krowy. Io zostaje oddana Argusowi, który ma jej pilnować. Nimfa codziennie pasie się na łąkach leżących obok rzeki swojego ojca Inacha. Przestrzenią komunikacji staje się samo zachowanie zwierzęcia, które próbuje zbliżyć się do rodzinnego domu:

Nie wiedzą ani Najady, ani ojciec nie wie, kim jest; idzie za ojcem, za siostrami, daje się głaskać i podziwiać. Ojciec rwie trawę, jałówce podaje, ona dłoń liże, ręce ojcowskie całuje. Płacze; gdyby mówić umiała, błagałaby ratunku, wymówiłaby swe imię, powiedziała, co się stało (Owidiusz 1995, 29).

Dźwięki wydawane przez zwierzę należą nadal do przestrzeni pozaludzkiej. Taki stan trwa do chwili, w której zbolały ojciec dzięki pismu rozpoznaje w krowie swą córkę:

- O ja nieszczęsny! - woła ojciec Inach; płacząc, obejmuje rogi i śnieżny kark jałówki.

- O ja nieszczęsny! - szlocha. - Czy to ty, moja córka, której szukam wszędzie? Tyś to niepoznana a odnaleziona? Już żal po tobie nie był tak bolesny. Zamilcz - mówić się nie staraj, bo tylko z głębi serca wzdychasz i rykiem odpowiadasz na moje słowa, tylko to potrafisz (Owidiusz 1995, 29).

Ryk staje się dla ojca Io substytutem słów, które chce mu przekazać córka. Rozpoznanie kobiety w ciele krowy nie przynosi jednak rozwiązania problemu samej przemiany. Nimfa, zdradzając swoją tożsamość ojcu, naraża się ponadto na zemstę Hery. Bogini uzyskuje bowiem potwierdzenie niewierności swojego męża. Io zostaje odebrana ojcu i zmuszona do ucieczki przed gryzącym ją owadem (wcieleniem bogini gniewu). Po interwencji Zeusa udaje się jej jednak wrócić do stanu pierwotnego:

I oto Io odzyskuje dawną postać, staje się tym, czym była. Schodzi sierść z jej ciała, znikają rogi, zmniejszają się oczy, zwęża się pysk, wracają ręce i ramiona. Kopyto na pięć palców się rozdziela. Nic już nie ma z jałówki, tylko wdzięk pozostał. Uszczęśliwiona Nimfa staje na dwóch nogach, prostuje się, boi się tylko mówić, by przypadkiem nie usłyszeć ryku zamiast głosu, wreszcie nieśmiało, z wolna wypowiada słowa (Owidiusz 1995, 32).

Po odzyskaniu dawnej postaci nimfa obawia się jedynie wydania z siebie głosu, ponieważ to on łączył ją ze zwierzęcością. Nie jest pewna tego, czy powracając do ludzkiego ciała, utraciła możliwość wydawania zwierzęcych dźwięków. Istotne jest również to, że pismo (jedyny „ludzki” sposób 
komunikacji dostępny nimfie zmienionej w zwierzę) przechodzi w mowę (żywy język, taki, który nie odrywa słowa od aktualności)._Wypowiadane niepewnie słowa zaświadczają o powrocie do świata ludzi, nie redukują jednak wartości wspólnotowego wyrażania.

\section{Ślady}

Jak twierdzi Walter Jackson Ong, pismo jest językiem, który nie podlega „,bezpośredniemu sprawdzeniu” (Ong 2011, 131). Taki sposób przekazywania myśli „odrywa się” od autora, nie można go poddać weryfikacji podczas rozmowy. Ta ,śmierć autora” wypowiedzi ma również swoje znaczenie dla zagadnienia narracji. Carl Ginzburg przywołuje opowieść z tradycji chińskiej, która przypisuje wynalezienie pisma urzędnikowi zafascynowanemu odciskami ptaka na piasku. Pismo wiąże się zatem w sposób nieodzowny z rytuałem tropienia znaków: „Myśliwy byłby pierwszym, który opowiada historię, ponieważ zdolny jest do czytania spójnych wydarzeń z niemych śladów (o ile nie niedostrzegalnych) pozostawionych przez drapieżniki" (Ginzburg 1980, 61). Zdolność odczytywania takich kodów była właściwa wszystkim ludziom żyjącym blisko natury (tropienie zwierząt). Powróćmy jednak do przyziemnej intuicji, która ,,rozpowszechniła się po całym świecie bez ograniczeń (...) i w konsekwencji bardzo oddaliła się od wszelkich form wiedzy wyższej zarezerwowanej dla uprzywilejowanych" (Ginzburg 1980, 44). Badacz zwraca uwagę na konieczność fizycznej i umysłowej bliskości zwierząt i ludzi. Nie jest to jednak relacja równościowa - znaki, odczytywane ze śladów zwierząt, są również znakami wykorzystywanymi do stosowania przemocy. Człowiek nie jest jedynie odbiorcą zrozumiałego ,,alfabetu” zwierząt, staje się również oprawcą (myśliwym na tropie). Ginsburga zajmuje jednak głównie sam fakt doświadczenia wspólnej wszystkim wiedzy, która „łączy ściśle zwierzę ludzkie z innymi rodzajami zwierząt” (Ginzburg 1980 , 44). Podobnie rzecz ma się u Derridy - w jego przekonaniu pismo to nieobecność i zwłoka, a przede wszystkim swoiście rozumiany koniec:

Pismo niesie śmierć. Można by się pobawić: pismo jako malowanie istoty żywej, utrwalającej zwierzęcość, zoografia, jest, zdaniem Rousseau, pismem dzikich. Którzy, jak wiemy, są również tylko myśliwymi: ludźmi od zoogreia, od chwytania istot żywych. Pismo byłoby obrazkowym przedstawieniem upolowanego zwierzęcia: magicznie pojmowanego i magicznie uśmierconego (Derrida 2011, 372).

Przypomnijmy wypowiedź Platona, zdaniem którego pismo, nazwane przezeń w Fajdrosie nieludzkim, wiązać należy ze śmiercią:

Ty jesteś ojcem liter; zatem przez dobre serce dla nich przypisałeś im wartość wprost przeciwną tej, którą one posiadają naprawdę. Ten wynalazek niepamięć w duszach ludzkich posieje, bo człowiek, który się tego wyuczy, przestanie ćwiczyć pamięć; zaufa pismu i będzie sobie przypominał wszystko z zewnątrz, ze znaków obcych jego istocie, a nie $\mathrm{z}$ własnego wnętrza, z siebie samego. Więc to nie jest lekarstwo na pamięć, tylko środek na przypominanie sobie. Uczniom swoim dasz tylko pozór mądrości, a nie mądrość prawdziwą. Posiędą bowiem wielkie oczytanie bez nauki i będzie się im zdawało, że 
wiele umieją, a po większej części nie będą umieli nic i tylko obcować z nimi będzie trudno; to będą mędrcy z pozoru, a nie ludzie mądrzy naprawdę (Platon 1958, 274).

Wśród wielu poruszanych tu zastrzeżeń (formułowanych wobec pisma) najistotniejszym, w kontekście Io, wydaje się oddzielenie żywego słowa od teraźniejszości. Transformacja ciała spełnia się jednak dopiero wtedy, gdy widoczny jest ślad przeobrażenia. Element obcości, wszczepiony w nowy kształt (tu ,,białą jak mleko jałówkę”), musi zaświadczać o dokonanej przemianie, $\mathrm{w}$ przeciwnym razie nie byłoby możliwe rozpoznanie. Znakiem odróżniającym Io od innych jasnych krów jest właśnie zdolność pisania: „Zamiast słów kopytem znaczy litery na piasku, smutną przemianę swej postaci opowiada" (Owidiusz 1995, 28-29). Historię nimfy Io można traktować jako jedną z opowieści o powstaniu pisma w kulturze zachodniej. Mit należy zatem zaliczyć do narracji ajtiologicznych, czyli takich, które wyjaśniają sposób powstania zjawiska. Owidiusz stwierdza, że zwierzę dokonuje przeobrażenia $\mathrm{w}$ znaki (w oryginale: littera pro verbis quam pes in puluere duxit). Zapisane słowa zaświadczają o dokonanej metamorfozie człowieka w zwierzę, a jednocześnie są jej zaprzeczeniem, bowiem nie dokonała się ona w pełni, czyli tak, by pozbawić krowę możliwości komunikowania się w formie liter. Somatyczne doświadczenie bycia zwierzęciem pozwala na oddanie jego sposobu przeżywania w literach (kopyto umożliwia przekaz informacji).

Równie istotna jest sama forma zapisu, gdyż - jak przypomina Daniel Heller-Roazen, cytując szesnastowiecznego artystę Geoffroya Tory'ego znaki składające się na imię nimfy to: „dwie litery, z których ukształtowane zostały wszystkie inne litery attyckiego alfabetu" (Heller-Roazen $2012,120)$. Io nie tylko porozumiewa się z otoczeniem, ale rozpoczyna erę piśmienności. Trafnie ujmuje to amerykański komparatysta: „Pismo jest zatem wynalazkiem krowy - pozostałością, która wytworzyła się w ostatecznym zaniku głosu" (Heller-Roazen 2012, 121).

Zjawisko metamorfozy ukazuje więc spotkanie natury i kultury; człowieka, który chcąc wyodrębnić własną różnorodność, próbuje porzucić tkwiącą w nim zwierzęcość czy szerzej: związek z naturą. Uwidacznia się tutaj pewien paradoks: natura była zawsze postrzegana jako pierwotny obcy (nie-ludzki element rzeczywistości), choć sama określała jednostkę (Soper 2000, 125). Zaryzykujmy stwierdzenie, że tego rodzaju podziały, wynikające przecież z różnic kulturowych, w dobie emancypujących się podmiotów nieantropocentrycznych można przenieść na grunt relacji człowiek-świat. Logiczną konsekwencją zmiany paradygmatu myślenia o istotach żywych winno być uwzględnienie perspektywy pozaludzkiej w nauczaniu. Problem życia rozpatrywany jest najczęściej w oderwaniu od źródeł przyrodniczych i sytuowany w sferze wartości duchowych. Uznanie, że egzystencja nie ma jedynie wymiaru kulturowego i jest ściśle związana ze spojrzeniem biologicznym, otwiera przed podmiotem poznającym sferę kultury zjednoczonej z jej naturalnym pochodzeniem. Problemy poruszane w ramach animal 
studies mają zatem duży potencjał poznawczy i powinny być stosowane w kształceniu polonistycznym (Wójcik-Dudek 2012, 252). W procesie edukacji należy uwzględnić zarówno próby stematyzowania doświadczenia bohaterów nieantropocentrycznych, jak i budowanie postawy wrażliwości wobec innych gatunków. Pokazanie perspektywy zaangażowania powinno objąć przegląd zjawisk obserwowanych w różnych okresach historycznych tak, by udowodnić, iż temat ten jest obecny w nauce od dawna. Już przecież Owidiusz w pierwszym zdaniu swojego utworu napisał, że jego celem nie jest wyznaczanie wyraźnych granic, a jedynie głoszenie nieuchronności zmian. Jeśli czegokolwiek możemy być zatem pewni, to jedynie tego, że zarówno człowiek, jak i zwierzę należą do tego samego porządku natury, którą kultura próbuje wyrazić. Warto zatem nadal poszukiwać skuteczniejszego sposobu przekazywania doświadczenia zwierząt.

\section{Bibliografia:}

Arystoteles, 1982, Zoologia, Siwek P. (przeł.), Warszawa.

Barcz Anna, 2013, Posthumanizm i jego zwierzęce odgłosy w literaturze, „Teksty Drugie", nr 1/2.

Baumeister Roy F., 2011, Między natura i kultura, Stefańska-Szewczuk D. (przeł.), Warszawa.

Cassirer Ernst, 1977, Esej o człowieku. Wstęp do filozofii kultury, Staniewska A. (przeł.), Warszawa.

Derrida Jacques, 2011, O gramatologii, Banasiak B. (przeł.), Łódź.

Ginzburg Carl, 1980, Signes, traces, Pistek. Racines d'un paradigme de l'indice, „le debat”, nr 6; cyt za: Mytych-Forajter Beata, 2005, Przyziemne intuicje. Carla Ginzburga „,Znaki, oznaki, poszlaki” w: Nawarecki A., Bogdanowska M. (red.), Skala mikro w badaniach literackich, Katowice.

Grochowski Grzegorz, Ubi leones, „Teksty Drugie” 2013, nr 1/2.

Heller-Roazen Daniel, 2012, Echolalie. O zapominaniu języka, Brzezicka B. (przeł.), Gdańsk.

Martuszewska Anna, 1993, Literackie zwierzyńce: wstępna lustracja, w: Literacka symbolika zwierząt, Gdańsk.

Nawarecki Aleksander, 2011, Zoofilologia w: Kurek J., Maliszewski K. (red.), Zwierzęta i ludzie, Chorzów.

Ong Walter Jackson, 2011, Oralność i piśmienność. Słowo poddane technologii, Japola J. (przeł.), Warszawa.

Ong Walter Jackson, 2009, Osoba, świadomość, komunikacja. Antologia, Japola J. (przeł.), Warszawa.

Owidiusz, 1995, Metamorfozy, Kamieńska A., Stabryła S. (przeł.), Wrocław.

Platon, 1958, Fajdros, Witwicki W. (przeł.), Warszawa.

Platon, 1958, Protagoras, Witwicki W. (przeł.), Warszawa. 
Przybyła Wojciech, 2011, Kulturowa semantyka motywu zwierząt, ,,Teksty Drugie", nr 3.

Puk Marta, 2013, Mitologia w wygnańczych utworach Owidiusza, Poznań.

Soper Kate, 2000, Coupe L. (red.), The idea of nature, w: The green studies reader. From Romanticism to ecocriticism, London-New York.

Wójcik-Dudek Małgorzata, Zwierzęta a dydaktyka literatury: wokół szkolnej lektury powieści Olgi Tokarczuk „Prowadź swój pług przez kości umarłych”, „Postscriptum Polonistyczne” 2012, nr 2 (10).

\section{O Autorze:}

Krzysztof Witczak - doktorant w Zakładzie Literatury XX wieku, Teorii Literatury i Sztuki Przekładu Wydziału Filologii Polskiej i Klasycznej na Uniwersytecie im. Adama Mickiewicza w Poznaniu. Pisze pracę doktorską, w której zajmuje się zagadnieniem cielesności w najnowszej prozie polskiej. Współredaktor kilku monografii naukowych z zakresu studiów nad obcością. 
